\title{
Relationship between home fruit and vegetable availability and infant and maternal dietary intake in African American families: Evidence from the Exhaustive Home Food Inventory
}

\author{
Maria Bryant, PhD (UK)[Research Fellow], \\ Clinical Trials Research Unit, University of Leeds, Leeds, LS21 1HU, UK, Phone: 0113-343-7632 \\ FAX: 01144(0)113 3431,m.j.bryant@leeds.ac.uk \\ June Stevens, PhD SRD[Professor][Chair], \\ Department of Nutrition, Gillings School of Global Public Health, University of North Carolina, \\ Chapel Hill, NC 27599, USA, Phone: 919-966-7218 FAX: 919-966-7216, june_stevens@unc.edu

\section{Lily Wang,} \\ Research Statistics and Programming, Department of Nutrition, Gillings School of Global Public \\ Health, University of North Carolina, Chapel Hill, NC 27599, USA, Phone: 919-843-8642 FAX: \\ 919-966-7216, lily_wang@unc.edu

\section{Rachel Tabak, PhD, Department of Nutrition, Gillings School of Global Public Health, University of North Carolina, Chapel Hill, NC 27599, USA, Phone: 919-843-0603 FAX: 919-966-6264, tabak@email.unc.edu \\ Judith Borja, PhD[Deputy Director], and \\ Office of Population Studies Foundation, University of San Carlos, Talamban Campus, Cebu City, Philippines, Phone (63) 032-3460102 FAX (63) 032-3466050, judithborja@gmail.com}

\section{Margaret E. Bentley, PhD[Professor] \\ Department of Nutrition, Gillings School of Global Public Health, University of North Carolina, Chapel Hill, NC 27599, USA, Phone: 919-966-9575 FAX: 919966 9159, pbentley@unc.edu}

\begin{abstract}
Background-The availability of foods in the home is likely to be related to consumption. We know of no studies that have reported this association in African American participants, and few studies have examined home food availability using objective methods.
\end{abstract}

Objective-This study aimed to assess the association between objective measures of fruits and vegetables in the home with reported infant and maternal diet in low income African Americans.

Design-A cross-sectional study design was used to compare food availability and dietary intake. The "Exhaustive Home Food Availability Inventory" used barcode scanning to measure food availability in the home. Maternal and infant diet was assessed by 24-hour recall.

Participants/setting-80 African American first-time mother/infant dyads were recruited from Wake and Durham counties in North Carolina.

\footnotetext{
(C) 2011 The American Dietetic Association. Published by Elsevier Inc. All rights reserved.

Corresponding and reader requests author: Dr. Maria Bryant, Clinical Trials Research Unit, University of Leeds. Leeds, LS2 9JT, UK. Publisher's Disclaimer: This is a PDF file of an unedited manuscript that has been accepted for publication. As a service to our customers we are providing this early version of the manuscript. The manuscript will undergo copyediting, typesetting, and review of the resulting proof before it is published in its final citable form. Please note that during the production process errors may be discovered which could affect the content, and all legal disclaimers that apply to the journal pertain.
} 
Statistical analyses performed-Adjusted mean dietary intake of infants and mothers was calculated within tertiles of food and nutrient availability using analysis of variance. The bootstrap method was used to estimate p-values and 95\% confidence intervals. Models were adjusted for mother's age, household size, shopping and eating out behavior.

Results-Infants and mothers living in homes in the highest tertile of availability of energy, nutrients, fruits and vegetables tended to have the highest consumption respectively; however, statistically significant associations were more likely to occur with infant diet than maternal diet. The relationship was strongest for infant consumption of fruit with an average of $103.3 \mathrm{~g}$ consumed by infants who lived in homes in the highest tertile of availability, compared to $42.5 \mathrm{~g}$ in those living in homes in the lowest tertile $(\mathrm{p}<0.05)$.

Conclusions-The availability of fruits and vegetables in the home was associated with intake of those foods in a sample of African American mothers and infants. Results support making changes in the home environment as a method of promoting changes in fruit and vegetable intake.

\section{Keywords}

food; availability; home; environment; African American; diet; shopping

\section{Introduction}

There is growing evidence that the environment is an important cause of obesity (1-6). A "toxic" or "obesogenic" environment has been described as one that provides an almost unlimited, convenient supply of highly palatable, energy dense foods, coupled with conditions that encourage sedentary behaviors and discourage physical activity (4). While meso- and macro-level environments such as neighborhoods and communities (7) are undoubtedly important, micro-level environments, specifically the home (2, 4-5, 8-9), may have a more direct influence on behaviors that are critical to obesity development in young children (10). Social factors in the home environment that are hypothesized to influence children's diets, include parents' eating habits and child feeding practices (10-13). Physical influences have focused mainly on the availability of foods (in particular, fruits and vegetables) in the home $(3,14)$. Several studies examining the relationship between home food availability and diet have found that increased availability of certain foods is related to the consumption of those foods $(9,14-24)$. The extensive work by Baranowski, Cullen, and others has demonstrated that home food availability/accessibility of fruits and vegetables is related to child food consumption $(3,14,21-22,25-26)$. This work has advanced our understanding of the dynamics between availability and intake, but is limited by its use of predefined checklists that assess only some of the foods in the home. Such a targeted data collection method can reduce the burden to study staff and participants; however, it restricts the information gained. An exhaustive inventory of all foods in the home can provide data that allows investigators to describe the total amounts of foods and nutrients available and provides a denominator for other forms of assessments (e.g. percentage of household energy available from fruits and vegetables). Previous work of this exhaustive nature has also been conducted predominantly in the homes of White populations (14), and to our knowledge, none have provided separate estimates for African Americans. Food selection is highly linked to culture, and it is likely that the foods in the home differ in ethnically and socially distinct households. Work is needed that examines different populations, particularly those known to be at higher risk for obesity. The purpose of this paper is to describe the association between home food availability of fruits and vegetables with infant and maternal diet in African American homes using the 'Exhaustive Home Food Availability Inventory' (EHFI); an open inventory method of measuring all the food in the home. 


\section{Methods}

\section{Participants}

Participants were recruited from those enrolled in "The Infant Care Project", a longitudinal study of African American first-time mother/infant dyads, who were observed in their home environment (27-29). Participants in the Infant Care Project were recruited through clinics for the Supplemental Food Program for Women, Infant and Children (WIC) in Wake and Durham counties in North Carolina. Consequently, all participants were below the poverty line. For the current study, we contacted 112 eligible mothers with $12-18$ month old infants and $80(71 \%)$ agreed to participate. The study design included plans for three assessments in each household, each separated by approximately two months. All participants of the Infant Care Project were eligible to take part. However, since our goal was to perform repeated measures of the same household environment, we considered participants ineligible after a move to a new residence. Of the 80 participating households, 64 were successfully measured three times, 10 were measured twice, and 6 were measured once; in sum producing 218 inventories. The main reason for not participating in the repeat assessments was change in residence. When multiple measures were available, the mean values were used for analyses. Participants were provided financial incentives for participating in the home food inventory research. This study was approved by the University of North Carolina public health institutional review board on research involving human subjects and all participants provided informed consent.

\section{Home food availability inventories}

The Exhaustive Home Food Availability Inventory (EHFI) was used to measure all foods and beverages in participant homes. This is an observational measurement tool that uses scanning technology to record the presence and description of home food availability. Full details of the method have been described previously (30). In brief, researchers systematically scan barcodes of food and beverage items using a FoxPro data entry programme (V6.0 The Sage Group ${ }_{P I c}$ ), which links UPC numbers to a reference database containing food identification and nutrient information. A commercially available database with 60,000 food items (Gregg London( $\odot$ ) was originally uploaded to serve as the basis of a reference database. The data entry programme has the capacity to upload information when barcodes are not available, which permits the exhaustive recording of all food items in the home. At the end of the study approximately 8,400 new items were added to the database.

Fruits and vegetables included those that were fresh, dried, frozen and canned or jarred, but excluded pickles. We generated our own generic barcodes to record foods that did not have a UPC barcode. These generic barcodes were linked to the nutrient reference database using nutrient composition information data from the U.S. Department of Agriculture (USDA) Standard Reference(31)

\section{Dietary intake}

Twenty-four hour dietary intake records were collected for infant and mother using the Minnesota Nutrition Data System for Research (NDSR, 2005) (University of Minnesota Nutrition Coordinating Center, Minneapolis); a Windows based dietary analysis program designed for the collection and analysis of 24-hour dietary recalls. Recalls were performed by trained researchers with the mother reporting intake for her infant. Initial recalls were performed in person during a home visit and subsequent recalls were performed via telephone interviews. 


\section{Other Measurements}

In addition to the food inventories, other measures were taken by trained staff during home assessments including, anthropometry and self-reported information on age, household size and composition, food shopping behaviors and frequency of eating out. Adult height was measured using a portable stadiometer to the nearest $0.5 \mathrm{~cm}$. Infant recumbent length was measured using a portable rigid length board to the nearest $0.1 \mathrm{~cm}$. Weight was measured on an electronic digital scale to the nearest $0.1 \mathrm{~kg}$. The number, gender and ages of all members of the household were obtained. Shopping behaviors were measured using 3 items that queried: usual shopping frequency, number of days since last shop and whether this was a large or small shop. Participants also reported the number of times per week that they usually consumed breakfast, lunch, dinner and snacks outside the home. A weighted score was used to adjust for meal size, with 1.5 assigned to dinner/supper eaten outside the home and 1.0 assigned to all other meals, including snacks.

For analytic purposes, a weighted score was also created to indicate household size adjusted for differences in energy needs. Weights were defined using the age and gender appropriate energy intake from the Dietary Reference Intakes (DRI) (32). For each household member, a value was created expressed as a proportion of the energy allowance relative to that of an adult female (2200 kcal per day), and the values were summed to create the household score.

Recruitment was on a rolling basis and data were collected over a 14 month period, with approximately 2 months between home food availability inventories. Diet data were collected within approximately 2 months of the first inventory, with an average of 10 days between infant 24-hour recalls.

\section{Statistical methods}

Food availability variables were categorized into tertiles, with the lowest amount acting as the reference. Adjusted mean dietary intake levels within tertiles of food and nutrient availability were calculated using linear regression models for each food group and nutrient studied. Because the dietary intake variables were skewed, the bootstrap method was used with 10,000 replications to estimate $\mathrm{p}$-values and 95\% confidence intervals (33). Models were adjusted for mother's age, household size, shopping and eating out behavior. Infant age, infant gender, birth weight and infant weight at visit 1 were considered as covariates, but none of these were significant at 0.05 level and were subsequently removed from the models. Bootstrap estimates were obtained using R (R Foundation for Statistical Computing, 2006. Vienna, Austria). Other analyses were performed using SAS (version 9.1, SAS Institute, Inc., Cary, NC).

\section{Results}

Descriptive information on the participants is shown in Table 1. The mean age of mothers and infants was 24.7 years and 23.3 months respectively. Seventy-one percent of mothers and $24 \%$ of the infants studied were overweight or obese.

Table 2 shows the intake of nutrients for infants and mothers for each tertile of food availability. There was a trend for higher energy intake in infants and mothers in homes with the highest availability of total energy; however, this was not statistically significant. Similarly, intake of fat (g) and fiber (g) was higher when availability of these nutrients was greater, although again, non-significant.

Intake of total fruit (g) was significantly greater in infants who lived in homes with the greatest availability of fruit, with an average of 103.3 grams of fruit consumed, compared to 42.5 grams in infants living in homes with the least availability of fruit $(56.4 ; 95 \%$ CI: 6.5, 
109.3). The relationship was similar when examining fruit intake when expressed as the number of servings $(0.54 ; 95 \%$ CI: $0.09,1.02)$. Maternal intake of fruits (expressed as grams or number of servings) was also greater in households with the highest availability of fruits, but these findings were not statistically significant.

The relationship between the availability of vegetables and their intake was similar to that of fruits (Table 2). Infants living in homes with higher availability of vegetables consumed over twice as many vegetables (grams and servings) compared to infants living in homes with the lowest amount of vegetables available. However, owing to large variability in intake data in the $3^{\text {rd }}$ tertile, statistically significant differences were only found between intake of vegetables the $2^{\text {nd }}$ and lowest (reference) tertiles of availability (intake in grams $27.8,95 \%$ CI: $5.3,49.8$; intake in servings $0.3695 \%$ CI: $0.05,0.67)$. Maternal intake of vegetables was similar to that of fruit; with greater intake in mothers living in homes with higher availability; albeit non-significant.

Infants and mothers living in homes with a greater proportion of energy derived from fruits and vegetables (Kcals available from fruit or vegetable / total Kcals available in the home from all foods) tended to consume more fruits and vegetables (Figures 1 and 2). However, the strength of this relationship was less than that observed for availability expressed in grams or servings. For infants, homes with the highest proportion of energy derived from fruits were significantly more likely to consume fruit, whether expressed in grams (58.6, 95\% CI: 9.3, 110.5) (Figure 1) or as number of servings of intake $(0.54,95 \%$ CI: 0.10, 1.01) (Figure 2).

\section{Discussion}

This study aimed to assess the association between fruits and vegetables in the home and infant and maternal diet in low income African Americans. These data provide evidence of a link between availability of fruits and vegetables in the home and dietary intake of fruits and vegetables for mothers and their infants. For the most part, the findings consistently show that greater availability was associated with greater intake, although associations were not always statistically significant. Having more fruits and vegetables in the home was associated with higher intake of these types of foods by infants. For fruit, this relationship was found whether intake was expressed in terms of total grams, number of servings or percent energy derived from fruits. For vegetables the relationship was not significant when vegetables were expressed as percent energy available from vegetables. While the effect of fruit and vegetable availability was generally associated with greater intake in mothers, the relationship was generally less strong compared to infants.

Researchers have examined fruit and vegetable availability intake in other populations and using different methodologies $(9,14-24)$. For example, as part of the development of the Home Environment Survey, Gattshall et al. (34) found that fruit and vegetable availability and accessibility, parent modeling and parental policies were positively associated with fruit and vegetable consumption. In this work they used a self-report survey and queried the presence or absence of fruits and vegetables in the home rather than determining quantity of items. Other researchers have also used self-report measures and found associations between food availability and intake (18, 21-23, 34-35). These studies have provided information of the impact of home food availability on intake; however, because errors in self-report information could be correlated within individuals, it is possible that associations could be overestimated from these type of data. Spurrier et al. (36) performed direct observations of foods in the home and reported a strong positive association between the amount of fruits and vegetables available in the family home and fruit and vegetable intake scores from a self-report tool. Results were based on observation of foods within categories relevant to the 
national guidelines for healthy eating (Australian Guide to Healthy Eating (AGHE)), and diet data were collected using reports from parents on a dietary patterns questionnaire with 24 items based on the same guidelines. Findings from our study extend these results by confirming the positive correlations between availability and intake using exhaustive observational methods to record food availability and complete 24-hour dietary recalls to measure dietary intake.

The associations we found between availability and intake of fruits and vegetables were not as strong as might be hypothesised, given the intuitive nature of the association. Consistent with our expectations was that the diets of children would be more dependent on foods in the home than the diets of adults; intake of fruits and vegetables was less strongly associated with availability in maternal diet than that of their infants. This finding was likely related to more foods being eaten out of the home by mothers. Our adjusted model accounted for eating out behaviors among the mothers, but did not attempt to adjust for eating out across mothers and their infant, and we did not collect specific information on the number of meals eaten outside the home by the infants in the study. It is possible that fruits and vegetables were purchased specifically for consumption for infants, but this information also was not ascertained in this study. Another factor contributing to weaker associations in the mothers may be that our dietary analysis included fruits and vegetables available from mixed dishes; whereas the availability data did not include fruits and vegetables in mixed dishes.

This study is particularly useful because data were collected in the homes of African Americans who were of low socioeconomic status and have an increased need for potent interventions to improve nutrition. This group has fewer resources and is at increased risk of obesity compared to the general American population (37-38). Recruitment of African American families is often more difficult compared to White participants (39-40), and we were fortunate to have access to a sample of African American homes in which a good rapport had already been established with researchers. While the sample size may appear smaller than dietary assessment studies, this study was one of the largest to date to objectively measure the home food environment. Byrd-Bredbenner (41) conducted 100 home inventories, but only one inventory was performed in each home. Importantly, the method used researcher conducted, direct observations, which are less prone to error associated with memory, social desirability and compliance. Nevertheless, the lack of effect for some variables may be limited by the diet data, which have large confidence intervals, representing considerable variance between participant intake.

Since all the participants in this study were from a similar ethnicity and socioeconomic strata, potential impact of those variables could not be studied here. It is possible that home food availability may reflect the overall home environment including social (parent's practices in regard to meal times) and other physical (presence of a table for eating) factors. These factors were not measured in this study and would be of interest in future work.

Understanding the influence of foods available in the home on dietary intake has direct implications for the development of interventions to improve diet. Our results indicate that increasing the number of fruits and vegetables in the home might increase their consumption by infants. Further, caregivers may need to be encouraged to prepare fruits and vegetables for their own consumption in addition to that of their children. These conclusions must be tentative since this observational study cannot infer causality and is limited by antecedentconsequence uncertainty.. It may be that consumption of fruits and vegetables drives purchases, rather than vice-versa. Nevertheless, there is some evidence from intervention studies showing that increasing the availability of fruits and vegetables in homes leads to an increase in their consumption (42-43). 
In conclusion, this study provides further evidence that the availability of fruits and vegetables in the home is associated with intake of these foods. This work is unique in that it examined these associations in a sample of African Americans using an objective and exhaustive method of assessing foods in the home. Our work indicates that increasing the amount of fruits and vegetables in the homes of low income African American women could increase intake of those foods in women and their children and lends support to the conduct of intervention studies that increase the availability of health promoting foods in the home as a method of increasing intake.

\section{Acknowledgments}

\section{Funding disclosure}

Work described here was supported by funding from the NIH/NCI: R21 CA125735 Development of a tool to measure food availability in the home; and R01 HD042219 Infant Care, Feeding, and Risk of Obesity

\section{References}

1. Elinder LS, Jansson M. Obesogenic environments--aspects on measurement and indicators. Public Health Nutr. Mar; 2009 12(3):307-315. [PubMed: 18498677]

2. van der Horst K, Oenema A, Ferreira I, et al. A systematic review of environmental correlates of obesity-related dietary behaviors in youth. Health Educ. Res. Apr; 2007 22(2):203-226. [PubMed: 16861362]

3. Glanz K, Sallis JF, Saelens BE, Frank LD. Healthy nutrition environments: concepts and measures. Am. J. Health Promot. May-Jun; 2005 19(5):330-333. ii. [PubMed: 15895534]

4. Swinburn B, Egger G, Raza F. Dissecting obesogenic environments: the development and application of a framework for identifying and prioritizing environmental interventions for obesity. Prev. Med. Dec; 1999 29(6 Pt 1):563-570. [PubMed: 10600438]

5. Lobstein T, Baur L, Uauy R. Obesity in children and young people: a crisis in public health. Obes Rev. May; 2004 5(Suppl 1):4-104. [PubMed: 15096099]

6. Poston WS 2nd, Foreyt JP. Obesity is an environmental issue. Atherosclerosis. Oct; 1999 146(2): 201-209. [PubMed: 10532676]

7. Sallis J, Glanz K. Physical activity and food environments: solutions to the obesity epidemic. The Milbank Quarterly. 2009; 87(1):123-154. [PubMed: 19298418]

8. Swinburn BA, Caterson I, Seidell JC, James WP. Diet, nutrition and the prevention of excess weight gain and obesity. Public Health Nutrition. Feb; 2004 7(1A):123-146. [PubMed: 14972057]

9. Pearson N, Biddle SJ, Gorely T. Family correlates of fruit and vegetable consumption in children and adolescents: a systematic review. Public Health Nutr. Jun $18.2008: 1-17$.

10. Davison KK, Birch LL. Childhood overweight: a contextual model and recommendations for future research. Obesity Reviews. Aug; 2001 2(3):159-171. [PubMed: 12120101]

11. Faith MS, Scanlon KS, Birch LL, Francis LA, Sherry B. Parent-child feeding strategies and their relationships to child eating and weight status. Obes. Res. Nov; 2004 12(11):1711-1722. [PubMed: 15601964]

12. Birch LL, Fisher JO. Development of eating behaviors among children and adolescents. Pediatrics. Mar; 1998 101(3 Pt 2):539-549. [PubMed: 12224660]

13. Birch LL, Davison KK. Family environmental factors influencing the developing behavioral controls of food intake and childhood overweight. Pediatr. Clin. North Am. Aug; 2001 48(4):893907. [PubMed: 11494642]

14. Bryant M, Stevens J. Measurement of food availability in the home. Nutr. Rev. Feb; 2006 64(2 Pt 1):67-76. [PubMed: 16536183]

15. Reynolds KD, Hinton AW, Shewchuk R, Hickey CA. Social cognitive model of fruit and vegetable consumption in elementary school children. Journal of Nutrition and Education. 1999; 31:23-30. 
16. Raynor HA, Polley BA, Wing RR, Jeffery RW. Is dietary fat intake related to liking or household availability of high- and low-fat foods? Obes. Res. May; 2004 12(5):816-823. [PubMed: 15166302]

17. Patterson RE, Kristal AR, Shannon J, Hunt JR, White E. Using a brief household food inventory as an environmental indicator of individual dietary practices. Am. J. Public Health. Feb; 1997 87(2): 272-275. [PubMed: 9103109]

18. Neumark-Sztainer D, Wall M, Perry C, Story M. Correlates of fruit and vegetable intake among adolescents. Findings from Project EAT. Prev. Med. Sep; 2003 37(3):198-208. [PubMed: 12914825]

19. Munoz KA, Krebs-Smith SM, Ballard-Barbash R, Cleveland LE. Food intakes of US children and adolescents compared with recommendations. Pediatrics. Sep; 1997 100(3 Pt 1):323-329. [PubMed: 9282700]

20. Larson N, Story M. A Review of Environmental Influences on Food Choices. Ann. Behav. Med. Oct 3.2009

21. Kratt P, Reynolds K, Shewchuk R. The role of availability as a moderator of family fruit and vegetable consumption. Health Educ. Behav. Aug; 2000 27(4):471-482. [PubMed: 10929754]

22. Hearn M, Baranowski T, Baranowski J, Doyle C, Smith M, Lin L. Environmental influences on dietary behavior among children: availability and accessibility of fruits and vegetables enable consumption. J. Health Educ. 1998; 29:26-32.

23. Hanson NI, Neumark-Sztainer D, Eisenberg ME, Story M, Wall M. Associations between parental report of the home food environment and adolescent intakes of fruits, vegetables and dairy foods. Public Health Nutr. Feb; 2005 8(1):77-85. [PubMed: 15705248]

24. Fulkerson JA, Nelson MC, Lytle L, Moe S, Heitzler C, Pasch KE. The validation of a home food inventory. Int J Behav Nutr Phys Act. 2008; 5:55. [PubMed: 18983668]

25. Kirby SD, Baranowski T, Reynolds KD, Taylor G, Binkley D. Childrens Fruit and Vegetable Intake - Socioeconomic, Adult-Child, Regional, and Urban-Rural Influences. Journal of Nutrition Education. Sep-Oct; 1995 27(5):261-271.

26. Baranowski T, Domel S, Gould R, et al. Increasing Fruit and Vegetable Consumption among 4th and 5th Grade Students - Results from Focus Groups Using Reciprocal Determinism. Journal of Nutrition Education. May-Jun; 1993 25(3):114-120.

27. Sacco LM, Bentley ME, Carby-Shields K, Borja JB, Goldman BD. Assessment of infant feeding styles among low-income African-American mothers: Comparing reported and observed behaviors. Appetite. 2007; 49(1):131-140. [PubMed: 17336423]

28. Slining M, Adair LS, Goldman BD, Borja JB, Bentley ME. Infant overweight is associated with delayed motor development. The Journal of Pediatrics. 2010; 157(1):20-25e21. [PubMed: 20227724]

29. Slining MM, Adair L, Goldman BD, Borja J, Bentley M. Infant temperament contributes to early infant growth: A prospective cohort of African American infants. International Journal of Behavioral Nutrition and Physical activity. 2009; 6(51) doi:10.1186/1479-5868-1186-1151.

30. Stevens J, Bryant M, Wang L, Borja J, Bentley ME. Exhaustive measurement of food items in the home using a universal product code scanner. Public Health Nutrition. 2010 doi 10.1017/ S1368980010001837.

31. Department of Agriculture. USDA national nutrient database for standard reference. Release 19. 2006

32. Table 3-5 in Recommended Dietary Allowances. National Research Council, National Academy Press; Washington, D.C.: 1989.

33. Efron B. 1977 Rietz Lecture - Bootstrap Methods - Another Look at the Jackknife. Annals of Statistics. 1979; 7(1):1-26.

34. Gattshall ML, Shoup JA, Marshall JA, Crane LA, Estabrooks PA. Validation of a survey instrument to assess home environments for physical activity and healthy eating in overweight children. Int J Behav Nutr Phys Act. 2008; 5:3. [PubMed: 18190709]

35. Cullen K, Baranowski T, Owens E, Marsh T, Rittenberry L, de Moor C. Availability, accessibility, and preferences for fruit, $100 \%$ fruit juice, and vegetables influence children's dietary behavior. Health Educ. Behav. Oct; 2003 30(5):615-626. [PubMed: 14582601] 
36. Spurrier NJ, Magarey AA, Golley RK, Curnow F, Sawyer MG. Relationships between the home environment and physical activity and dietary patterns of preschool children: a cross sectional study. International Journal of Behavioral Nutrition and Physical Activity. 2008; 5(1):31. [PubMed: 18513416]

37. Differences in prevalence of obesity among black, white, and Hispanic adults - United States, 2006-2008. MMWR. Morb. Mortal. Wkly. Rep. Jul 17; 2009 58(27):740-744. [PubMed: 19609247]

38. Flegal KM, Carroll MD, Ogden CL, Curtin LR. Prevalence and trends in obesity among US adults, 1999-2008. JAMA. Jan 20; 2010 303(3):235-241. [PubMed: 20071471]

39. Shavers-Hornaday VL, Lynch CF, Burmeister LF, Torner JC. Why are African Americans underrepresented in medical research studies? Impediments to participation. Ethn. Health. Mar-Jun; 1997 2(1-2):31-45. [PubMed: 9395587]

40. Satia JA, Galanko JA, Rimer BK. Methods and strategies to recruit African Americans into cancer prevention surveillance studies. Cancer Epidemiol. Biomarkers Prev. Mar; 2005 14(3):718-721. [PubMed: 15767356]

41. Byrd-Bredbenner C, Abbot JM. Differences in Food Supplies of U.S. Households with and without Overweight Individuals. Appetite. 2009; 52:479-484. [PubMed: 19152822]

42. Haire-Joshu D, Elliott MB, Caito NM, et al. High 5 for Kids: The impact of a home visiting program on fruit and vegetable intake of parents and their preschool children. Prev. Med. Apr 9.2008

43. Tak NI, Te Velde SJ, Brug J. Are positive changes in potential determinants associated with increased fruit and vegetable intakes among primary schoolchildren? Results of two intervention studies in the Netherlands: The Schoolgruiten Project and the Pro Children Study. Int J Behav Nutr Phys Act. 2008; 5:21. [PubMed: 18439265] 


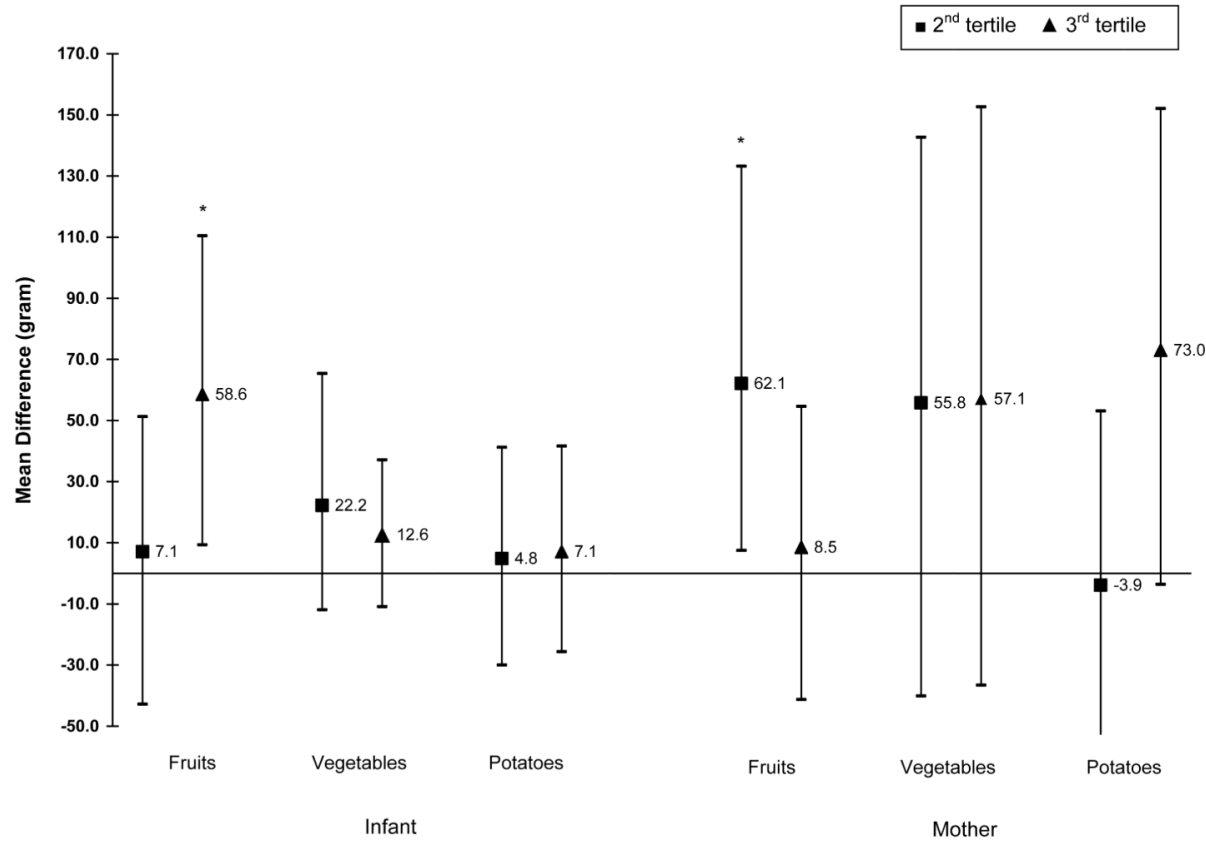

Figure 1.

Availability of $\%$ energy from fruits and vegetables in the home and dietary intake for infants and mothers: Difference in diet (grams) between tertiles of food availability. 


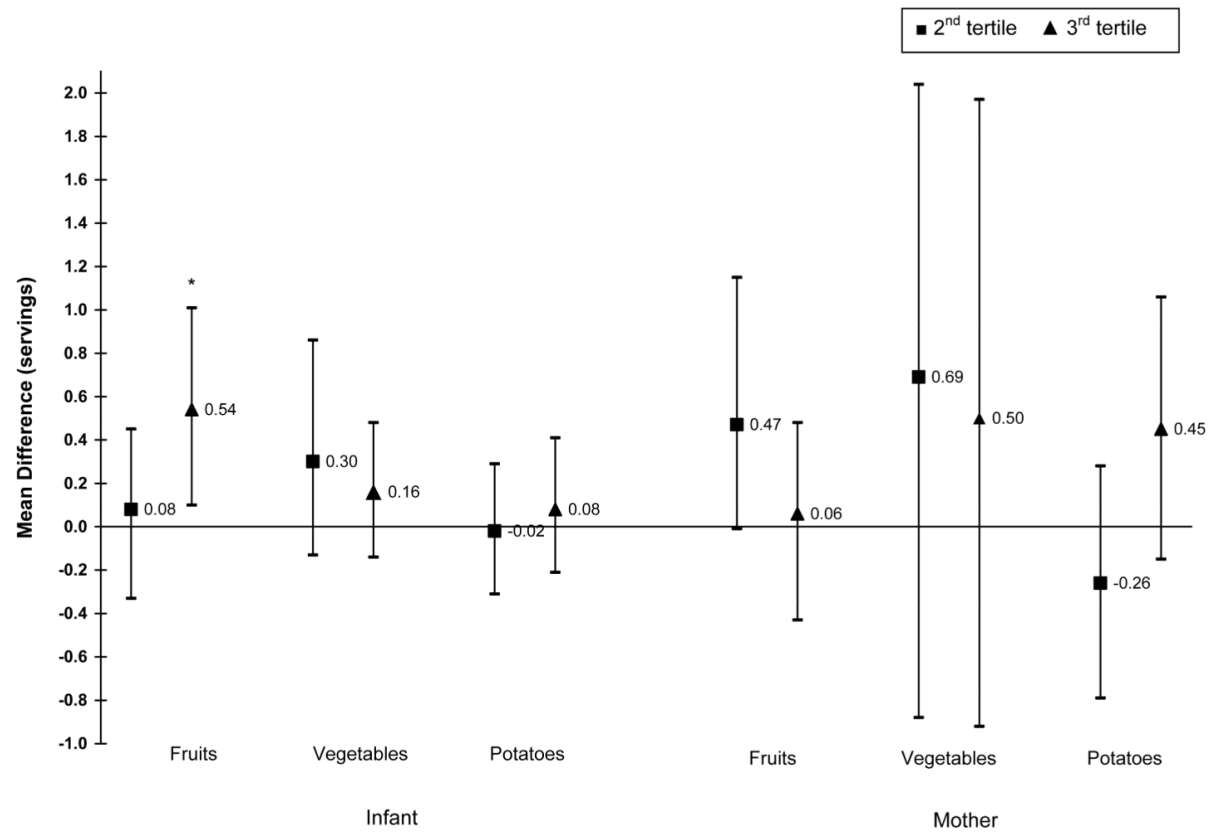

Figure 2.

Availability of \% energy from fruits and vegetables in the home and dietary intake for infants and mothers: Difference in diet (servings) between tertiles of food availability 
Table 1

Description of households at baseline

\begin{tabular}{|c|c|c|}
\hline & Mean / \% (n=80) & $\mathrm{SD}^{a}$ \\
\hline Mother's age (years) & 24.7 & 4.3 \\
\hline Mother's BMI (kg/m²) & 31.7 & 8.5 \\
\hline Underweight $(<18.5)$ & $2.5 \%$ & \\
\hline Normal weight (18.5 - 24.9) & $25.0 \%$ & \\
\hline Overweight (25 - 29.9) & $17.5 \%$ & \\
\hline Obese $(>=30)$ & $53.8 \%$ & \\
\hline Child's age (months) & 23.3 & 6.2 \\
\hline Child's weight for length z-score & 0.3 & 1.1 \\
\hline \multicolumn{3}{|l|}{ Child's weight status (\%) } \\
\hline Underweight $(<-1.64)$ & $5.0 \%$ & \\
\hline Normal weight $(-1.64-1.03)$ & $71.3 \%$ & \\
\hline Overweight (1.04 - 1.63) & $15.0 \%$ & \\
\hline Obese $(>=1.64)$ & $8.8 \%$ & \\
\hline Child's weight (kg) & 12.5 & 2.1 \\
\hline Children $^{a}$ per household & 1.5 & 0.8 \\
\hline Adults $^{b}$ per household & 1.9 & 0.9 \\
\hline Adult $^{b}$ men per household & 0.5 & 0.6 \\
\hline $\begin{array}{l}\text { No. meals eaten outside the home by mother } \\
\text { (per month) }{ }^{c}\end{array}$ & 33.7 & 20.3 \\
\hline \multicolumn{3}{|l|}{ Shopping frequency } \\
\hline Weekly & $12.5 \%$ & \\
\hline Bi-weekly & $40 \%$ & \\
\hline Monthly & $32.5 \%$ & \\
\hline Other & $15 \%$ & \\
\hline \multicolumn{3}{|l|}{${ }^{a}$ Standard deviation } \\
\hline
\end{tabular}


Table 2

Availability of nutrients and fruits and vegetables in the home and dietary intake by grams and number of servings for infants and mothers

\begin{tabular}{|c|c|c|c|c|}
\hline \multicolumn{4}{|c|}{ Infant diet $(n=71)$} & \multirow{2}{*}{$\begin{array}{c}\text { Maternal diet }(\mathrm{n}=67) \\
\begin{array}{c}\text { Difference from 1st tertile } \\
(95 \% \text { CI }) \text { p-value }\end{array}\end{array}$} \\
\hline Availability & Crude Mean & $\begin{array}{l}\text { Difference from 1st tertile } \\
(95 \% \mathrm{CI}) \mathrm{p} \text {-value }\end{array}$ & Crude Mean & \\
\hline Energy (Kcal) & Kcal & & Kcal & \\
\hline 1st tertile $(84073-171074)$ & 1288 & REF & 1753 & REF \\
\hline 2nd tertile (171074 - 259189) & 1414 & $223(-43,498) \mathrm{p}=0.10$ & 1915 & $236(-256,743) \mathrm{p}=0.33$ \\
\hline 3rd tertile (259189-548048) & 1446 & $237(-59,538) \mathrm{p}=0.12$ & 2079 & $353(-221,988) \mathrm{p}=0.25$ \\
\hline Fat $(g)$ & Fat $(\mathrm{g})$ & & Fat $(\mathrm{g})$ & \\
\hline 1st tertile $(3722-6722)$ & 48.5 & $\mathrm{REF}$ & 71.0 & REF \\
\hline 2nd tertile (6722 - 11024) & 49.8 & $6.4(-6.7,21.1) \mathrm{p}=0.35$ & 65.4 & $-0.9(-24.5,24.0) \mathrm{p}=0.95$ \\
\hline 3rd tertile (11024 - 32083) & 54.2 & $7.4(-4.9,19.2) \mathrm{p}=0.24$ & 86.9 & $16.9(-11.8,49.0) \mathrm{p}=0.26$ \\
\hline Fiber (g) & Fiber $(g)$ & & Fiber $(g)$ & \\
\hline 1st tertile $(379-1007)$ & 9.6 & REF & 10.4 & REF \\
\hline 2nd tertile (1007 - 1900) & 7.6 & $-1.8(-4.2,0.5) \mathrm{p}=0.13$ & 11.3 & $-0.6(-4.4,2.8) \mathrm{p}=0.71$ \\
\hline 3rd tertile $(1900-3483)$ & 10.1 & $0.7(-2.1,3.8) \mathrm{p}=0.62$ & 15.6 & $4.0(-0.7,9.5) \mathrm{p}=0.10$ \\
\hline Fruit (g) & Grams & & Grams & \\
\hline 1st tertile $(0-1557)$ & 42.5 & REF & 8.1 & REF \\
\hline 2nd tertile (1557 - 3589) & 86.0 & $41.9(-9.7,95.1) \mathrm{p}=0.11$ & 59.1 & $35.6(-25.7,99.2) \mathrm{p}=0.25$ \\
\hline 3rd tertile (3589 - 18103) & 103.3 & $56.4(6.5,109.3) p=0.03 *$ & 60.0 & $33.8(-5.6,81.9) \mathrm{p}=0.10$ \\
\hline Fruit (g) & Servings & & Servings & \\
\hline 1st tertile $(0-1557)$ & 0.35 & $\mathrm{REF}$ & 0.08 & REF \\
\hline 2nd tertile (1557 - 3589) & 0.70 & $0.31(-0.12,0.75) \mathrm{p}=0.15$ & 0.45 & $0.20(-0.33,0.72) \mathrm{p}=0.44$ \\
\hline 3rd tertile (3589 - 18103) & 0.93 & $0.54(0.09,1.02) \mathbf{p}=0.02 *$ & 0.59 & $0.31(-0.05,0.78) \mathrm{p}=0.10$ \\
\hline Vege (g) & Grams & & Grams & \\
\hline 1st tertile (944 - 4671) & 27.5 & $\mathrm{REF}$ & 85.9 & REF \\
\hline 2nd tertile $(4671-8842)$ & 59.8 & $27.8(5.3,49.8) p=0.02 *$ & 151.7 & $46.7(-43.3,132.9) \mathrm{p}=0.31$ \\
\hline 3rd tertile $(8842-36784)$ & 62.9 & $34.1(-4.0,86.6) \mathrm{p}=0.09$ & 145.4 & $33.1(-67.1,133.3) \mathrm{p}=0.49$ \\
\hline Vege (g) & Servings & & Servings & \\
\hline 1st tertile (944 - 4671) & 0.35 & REF & 1.16 & REF \\
\hline 2nd tertile (4671 - 8842) & 0.76 & $0.36(0.05,0.67) \mathrm{p}=0.02 *$ & 1.89 & $0.43(-1.04,1.62) \mathrm{p}=0.52$ \\
\hline 3rd tertile (8842-36784) & 0.78 & $0.41(-0.07,1.07) \mathrm{p}=0.11$ & 2.06 & $0.51(-1.08,2.14) \mathrm{p}=0.51$ \\
\hline Potatoes (g) & Grams & & Grams & \\
\hline 1st tertile $(0-756)$ & 42.7 & REF & 34.4 & REF \\
\hline 2nd tertile (756 - 2742) & 38.0 & $-7.6(-41.0,29.5) \mathrm{p}=0.70$ & 91.9 & $47.4(-14.9,115.3) \mathrm{p}=0.13$ \\
\hline 3rd tertile (2742 - 5584) & 57.6 & $12.9(-23.7,52.3) \mathrm{p}=0.52$ & 95.8 & $61.7(-6.5,133.7) \mathrm{p}=0.08$ \\
\hline Potatoes (g) & Servings & & Servings & \\
\hline 1st tertile $(0-756)$ & 0.40 & $\mathrm{REF}$ & 0.41 & REF \\
\hline 2nd tertile (756 - 2742) & 0.50 & $0.10(-0.22,0.42) \mathrm{p}=0.54$ & 0.95 & $0.59(-0.01,1.18) \mathrm{p}=0.05 *$ \\
\hline
\end{tabular}




\begin{tabular}{|c|c|c|c|c|}
\hline & & fant $\operatorname{diet}(n=71)$ & & Maternal diet $(n=67)$ \\
\hline Availability & Crude Mean & $\begin{array}{l}\text { Difference from 1st tertile } \\
\quad \text { (95\% CI) p-value }\end{array}$ & Crude Mean & $\begin{array}{l}\text { Difference from 1st tertile } \\
\quad \text { (95\% CI)p-value }\end{array}$ \\
\hline 3rd tertile $(2742-5584)$ & 0.49 & $0.03(-0.27,0.35) \mathrm{p}=0.86$ & 0.75 & $0.34(-0.19,0.89)=0.21$ \\
\hline
\end{tabular}

